\title{
Landscape small-scale mapping and sustainable development
}

\author{
Z. Sh. Gagaeva \& I. A. Kerimov \\ Department of Geology, Geophysics and Geochemistry, \\ Complex Institute of the RAS, Russia
}

\begin{abstract}
This paper deals with capabilities and methods of analysis of remote information. The objective of the analysis is preparation of the preliminary landscape map on the basis of Landsat image classification. Dichotomic grouping of the data was performed using $\mathrm{K}$-means method and various remote metrics. On each level iteration procedure was used. Classification result provide identification of various conditions of landscape cover on the basis of various classification levels detailed more and more on following levels. Classification provides grounds for detail identification of natural zonal types of landscapes. In this connection residential areas and significantly transformed natural areas are identified as well. Comparison of classification results with content of forestry map of USSR (1973) of scale 1:1 000 000, and geobotanical map of scale 1:4 000000 , allows reliable identification of basic types of landscape cover.
\end{abstract}

Keywords: landscapes, dichotomic grouping (classification), environmental management, sustainable development, spectral brightness.

\section{Introduction}

At the present time preservation of the ecological balance of natural environment and environmental management is a vital issue in scholarly disputes. Landscape is an immediate area of human and economic activities. Excessive human impact on landscape resulted in deterioration of landscape element interaction processes [1]. Moreover on numerous occasions backlash of the influence reached global scale.

In sustainable development concept among most important problems there is a problem of landscapes functional properties preservation. Development of 
regulation methods of human influence on landscapes and preservation of its sustainable development has special role among problems related to lands deforestation. The problem of support and management of economy is also of a special interest. When solving these problems there should be a clear-cut idea about natural-resources potential of the region, national heritages of environmental management and progressive forms, used in conditions of open society.

The freshness of the research consists in that the research was performed on the basis of primary available information use that provides relatively consistent results. Primacy (or minimality) of the information comes from the fact that currently researchers can not always conduct long-term field studies, however this stage of investigation, based on usage of remote sensing data, can be considered preliminary, followed by series of other stages.

\section{Creation of the landscape map on base of distance information}

Condition and dynamics of landscape cover over the last 10-15 years allows provision of first ideas about natural capital conditions. We examine the problems at a first approximation on the basis of Quick Look of Landsat images.

In the present message capabilities and methods of remote information analysis are presented. Small-scale landscape map development method for identification of landscape covering condition for specific observation period is shown (Landsat images, June 5/2001, image resolution 200x200 meters, band 3, $4,5)[3,4]$. Image of the Northern Caucasus, including Chechnya and Ingushetia, was used.

\subsection{Methods}

In spite of small territory $\left(15,5 \mathrm{~km}^{2}\right)$, Chechnya and Ingushetia are characterized with wide range of landscapes (from in-Caspian semi deserts to nival glacial belts Caucasus). Such diversity created primarily by contrast terrain and continental climate. They make necessary development of advanced strategy, aligned with environmentally sound use of natural resources. The image (used in the investigation) shows both flat and upland natural areas. Contrast diversity of the area reflects similarity of the obtained results.

The analysis is performed on the basis of dichotomous classification. It enables to explain without restraint (unquestionably) conceptual interpretation of detailed classes. In interpretation there is also used visible and available geographical information. To obtain more adequate image (picture) classification is performed by two metrics: of Euclid and normalized scalar product of vectors. The last metric provides division of classes, taking into account brightness characteristics.

The classification performed up to level 8, differentiating more than 200 classes. Discriminant analysis of the detailed classes according to channels values shows correspondence (accuracy) of the obtained results almost $80 \%$. By 
principal components method discriminant analysis axes for two classifications are integrated into one system. Use of this approach increases entropy of three images and provides equality of each factor entropy.

The reflections of region are shown in three different factors, fig.1.

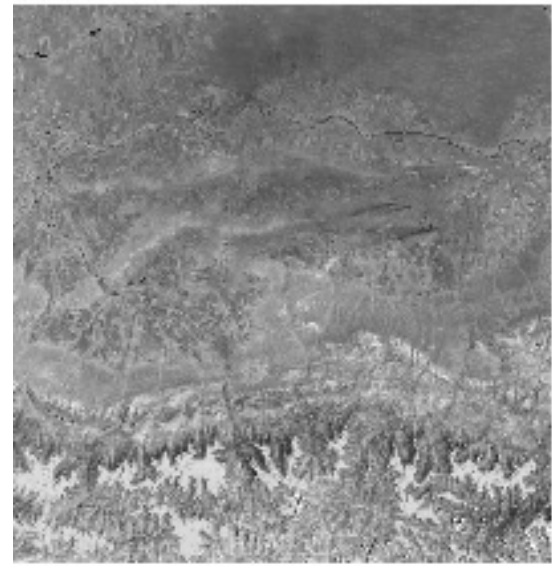

Component 1

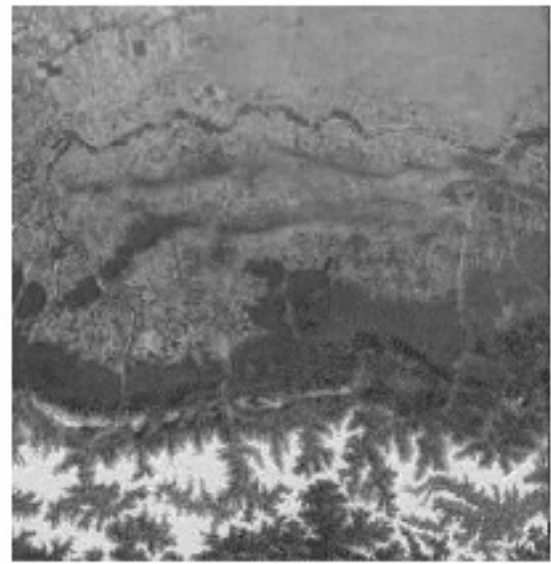

Component 2

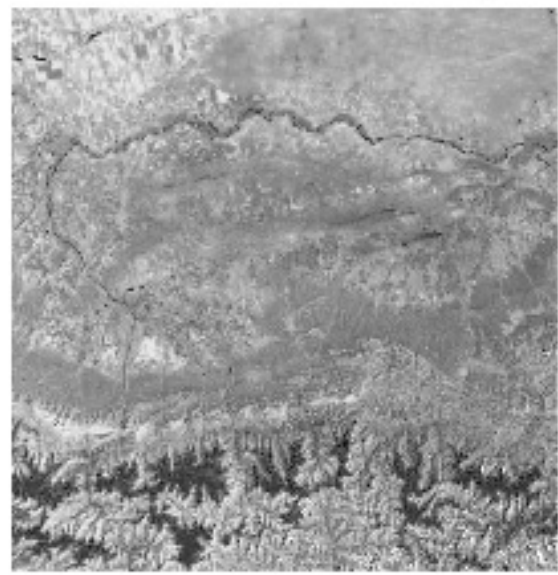

Component 3

Figure 1: The reflections of region by different factors (components).

\subsubsection{Results of classifications on different levels}

Each factor (component) contains mainly independent and complementary information. Classification on the basis of three factors using K-means method is taken as final. In contrast to standard classification procedure the classification performed enables to identify and reliably distinguish open water surfaces, builtover areas and surfaces with various humidity. 
The classification for first-fourth levels is shown in fig. 2.

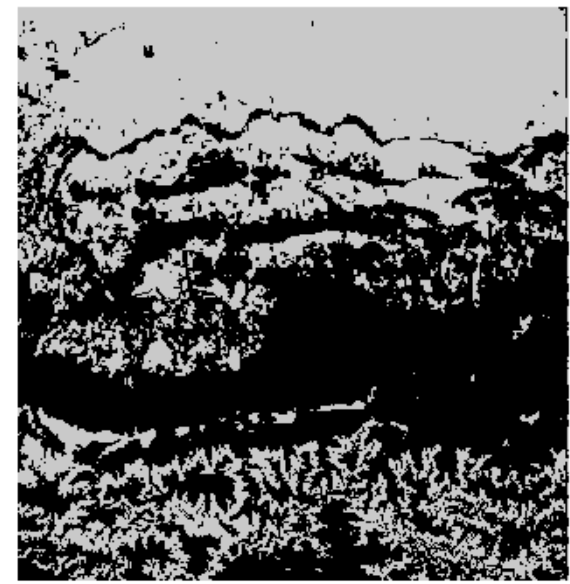

Level 1

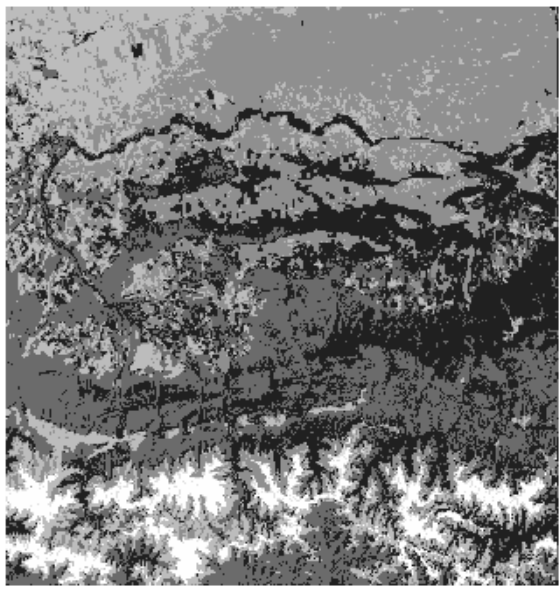

Level 3

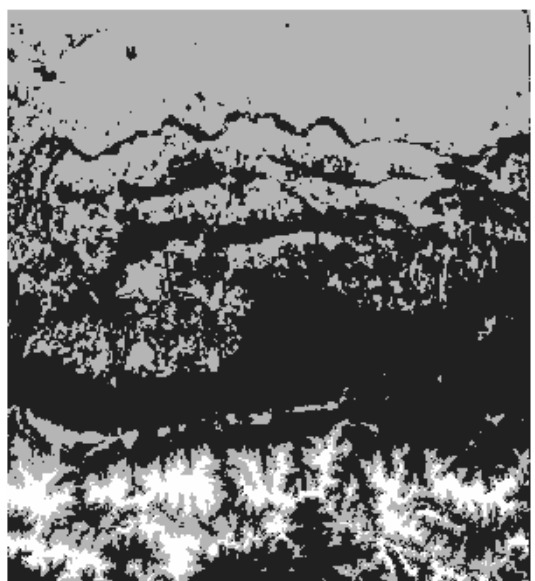

Level 2

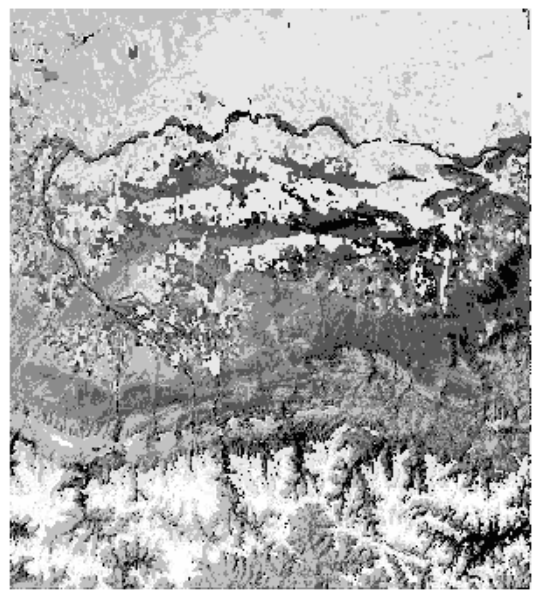

Level 4

Figure 2: $\quad$ Classification of image for different levels.

Sequential dichotomic division allows control of classification content complexity order. The first level includes 2 classes 1) open (treeless) landscapes (agricultural lands, moors, semi deserts, alpine meadows, 2) other classes, including snowfields. Level 2 includes snowfields and more typical areas within built-up lands. Level 4 rather distinctly shows various conditions forest and snowfields. Next level enables to reliable identify water bodies, conifer forests, forests with beech and hornbeam predominance. Landscapes without green cover, alpine meadows and others are detailed within alpine belt. More detailed 
semantic interpretation enables to identify belongingness to zones, various flanks, intermountain bottomlands, watershed and other relief elements.

2.1.1.1 Reliability of the results. Comparison of classification results with Atlas of USSR and geobotanical map enables to identify basic types of landscape cover. Natural characteristics of color intensity in three channels allow identification of forests with different crown densities.

Spectral brightness values reflect existing characteristics of landscape cover, fig.3.

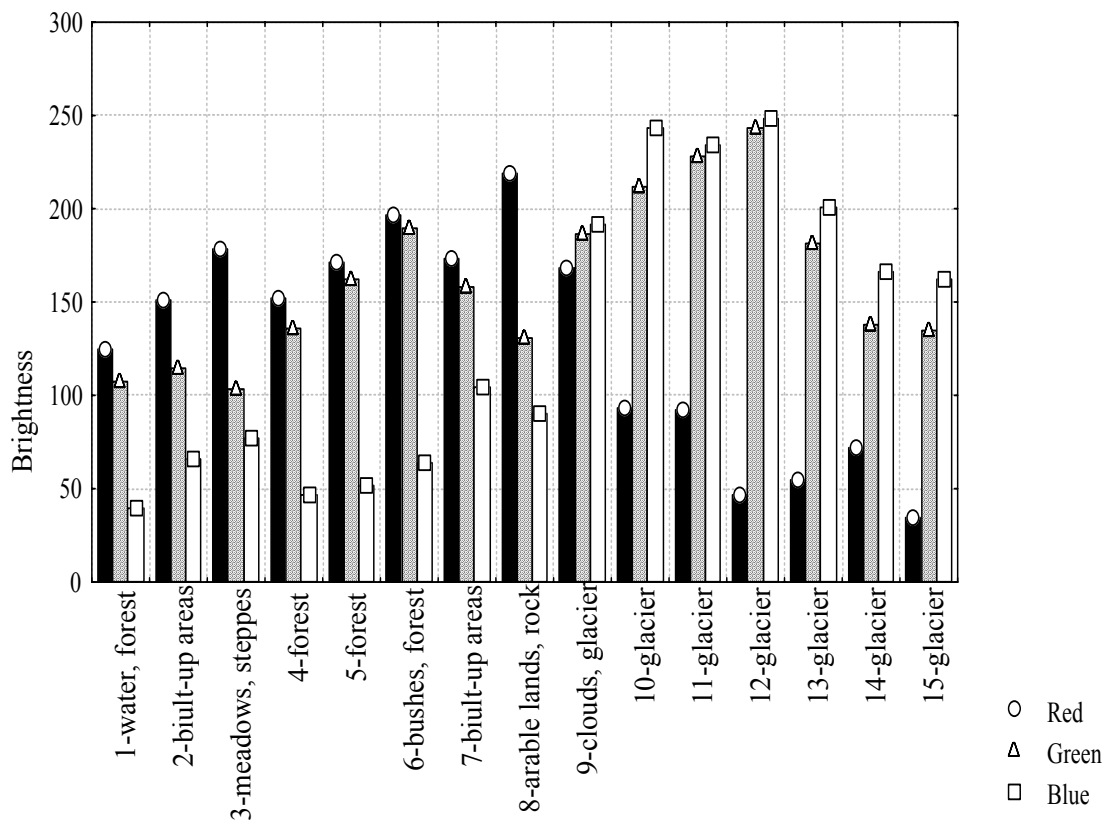

Classes

Figure 3: Classes of land cover and corresponding brightness value (fourth level).

Forests and snowfields (classification level 4) are represented in various conditions. For example, sparse or dense forests, hard or melting snowfields. By this means on the basis of generally accessible information and with the help of the presented methods generalized and detailed images of landscape cover were obtained, which can be used for various aims of environmental management and planning. The results are applicable for conducting assessment of agricultural lands condition and for identification of higher productive forests and particularly rich areas. All in all the image obtained is applicable for conducting environmental measures. 
The comparative analysis of past and more current images (1986 and 1999) helps to reveal the changes that took place in the area during the last 10-15 years. Their assessment allows making conclusions about the character and the scale of landscape transformation over the period of record. So as a result of anthropogenic load removal from steppe and forest-steppe landscapes of TerskoSunzhensky highlands and foothills the process of occlusion of landscapes supposedly with bushes and forests is observed.

Analysis of the available LandSat images, despite their low resolution, enables identification and resolution of problems related to the conditions of landscape cover, with further use of higher resolution images, making quite reasonable transition to the other scale of landscape cover assessments.

The complexity of landscape pattern is determined by landscape metrics [2]. The landscape map developed can provide the basis for development of landscape master plan, economically oriented measures, calling for shifting to sustainable development.

\section{Conclusion}

Based on the analysis conducted, the following conclusions can be stated:

1) Most of the changes in landscapes are related to the industrial (technogenic) impact, which is characterized as nature-demanding and nature-destructive. As a consequence the properties are destroyed, which can restore and normalize disturbed balance, geosystems are destabilized.

2) When reclaiming and using landscape-resource potential environmental constraints are not taken into consideration as a result of which renewable resources (forests, soils etc.) are overexploited in rates that exceed their recovering capabilities.

2) Scales of reclamation and exploitation have been changed, that caused qualitative changes in environment. As a consequence the landscapes suffer immense loads (increase of population density, deterioration of environmental conditions, and reduction of planting areas within settlements).

3) Due to the increased load, the territories, which used to have sufficient resource-recovering characteristics, are now scarce of resources (fresh water, vegetative cover, fresh air, etc.)

4) Development of different maps (landscape, ecological, landscape-ecological) is a basis for measuring environmental indicators on the different levels of assessments (from small-level to large-level), which ensure reasonable approach to the planning process for the corresponding activities.

5) Relation between landscape mapping and sustainable development of territories can be determined through the following points:

Sustainable development assumes implementation of some principles, among which an important emphasis is made on preserving high quality of the environment.

In the concept of sustainable development an important task is to preserve functional features of the landscapes. A special role in this process is given to development of methods and regimes of regulating anthropogenic pressure on 
the landscapes and maintaining their sustainable development. Today, landscape maps are considered as the basis for planning economical activities, and are an essential part of the assessments of environmental impact. In addition they are used in planning the development of networks of protected territories and landscape planning for complex environmental management, which corresponds to the sustainability concept.

Landscape maps allow identification of various problematic areas (agricultural and residential areas, deserted landscapes and other territories), for each of which there are corresponding indicators, which are aimed at ensuring sustainable development of landscapes.

\section{References}

[1] Gagaeva, Z.Sh., Landscape-ecology problems of Chechen Republic. Proceedings of International Landscape Conference "Landscape: Theory, Methods, Regional Researches, Practice”. Moscow, pp. 485-486, 2006.

[2] Puzachenko, Yu.G., Methodological basis of landscape measurement, Proceedings of the Russian Academy of Sciences. Geographical Series, 4, pp. 30-50, 1995.

[3] Puzachenko, Yu.G., Formation of the landscape structure (Methodology of studies), Moscow University Gerald, Series 5, Geography, 4, pp. 5-12, 1999.

[4] Puzachenko, Yu.G., Aleshchenko, G.M., Molchanov G.S., Multiplemeasured Analysis of Space Images, Proceedings of the Russian Academy of Sciences. Geographical Series, 4, pp. 80-90, 1999. 